\title{
First report of a secondary aortojejunal fistula diagnosed by double-balloon enteroscopy
}

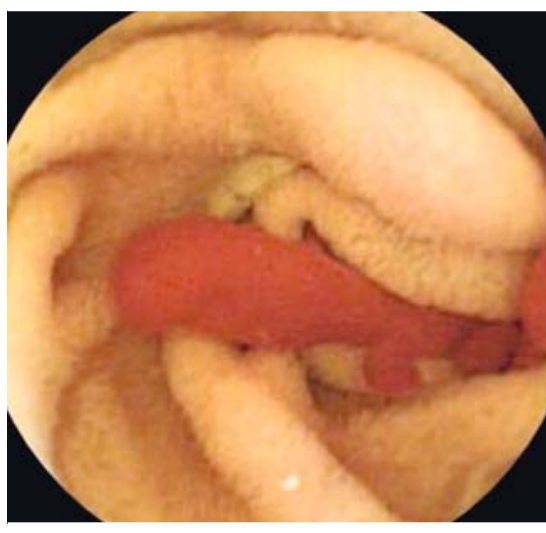

- Fig. 1 Small-bowel capsule endoscopy showed active bleeding in the proximal jejunum.

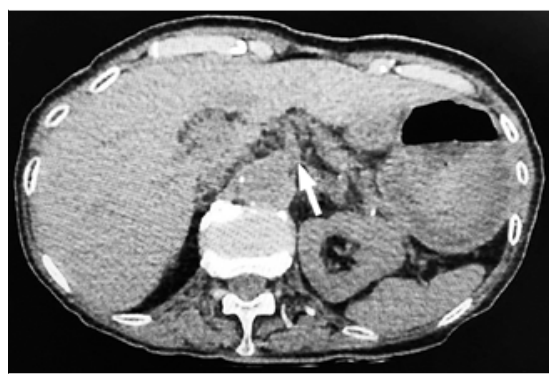

Fig. 2 Computed tomography scan. Arrow pointing to the jejunal loop lying in close proximity to the aortic graft.

Secondary aortoenteric fistula (AEF) can affect up to $1.6 \%$ of patients who undergo abdominal aortic aneurysm (AAA) repair, with the jejunum being involved only in up to $9 \%$ of the cases $[1,2]$. Secondary aortojejunal fistula (AJF) is a very rare, life-threatening condition, which may result in catastrophic gastrointestinal (GI) bleeding [3].

An 86-year-old woman with intermittent severe obscure-overt GI bleeding (negative upper and lower $\mathrm{Gl}$ endoscopies) was transferred as a tertiary referral to our institution for further investigation and management.

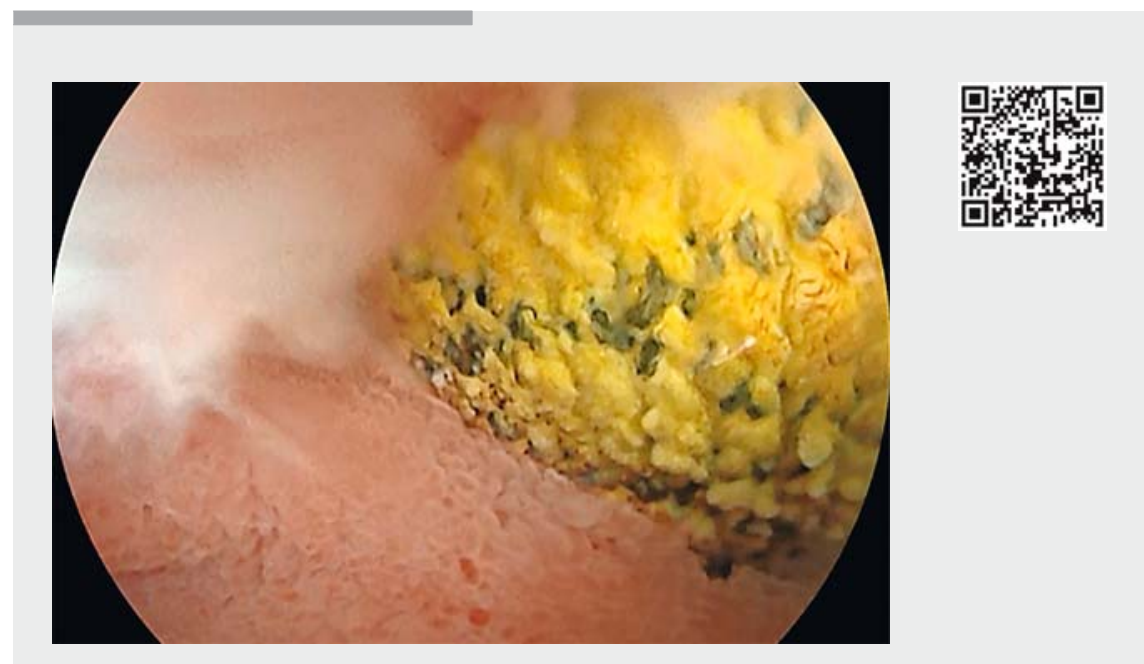

Video 1 Definitive diagnosis of an aortojejunal fistula was made when the external surface of part of the Dacron graft was seen to bulge through the jejunal wall.

Small-bowel capsule endoscopy had shown active bleeding within the proximal jejunum ( $\triangleright$ Fig. 1 ). The patient's history of AAA Dacron graft repair 9 years previously, raised our suspicion of a possible AEF. Although cross-sectional imaging had demonstrated close proximity of a jejunal loop to the aortic Dacron graft, the scan was deemed to be inconclusive ( Fig. 2).

We performed an urgent antegrade double-balloon enteroscopy (DBE) for direct endoscopic assessment of the small bowel ( $\bullet$ Video 1$)$. Our suspicions were confirmed and a definitive diagnosis of an AJF was clinched when part of the external surface of the Dacron graft was seen to bulge through the jejunal wall at an estimated insertion depth of $60 \mathrm{~cm}$ beyond the pylorus. No active bleeding was seen at the time of the endoscopy. Vascular surgeons, in agreement with the anesthesia team, deemed surgical management to be of very high risk because of the patient's comorbidities and the complexity of the surgical procedure; there- fore palliative care was recommended. The patient died 4 months later as a result of recurrent episodes of GI bleeding, after refusing blood transfusions.

In view of the associated mortality that ranges between $22 \%$ and $100 \%$, prompt, definitive diagnosis of AEF remains critical [3]. To the best of our knowledge, this is the first report of AJF identified by DBE, and highlights the effectiveness of this endoscopic modality in providing an irrefutable diagnosis of AEF when this lies beyond the duodenum.

Endoscopy_UCTN_Code_CCL_1AC_2AB

\section{Competing interests}

Dr. Despott has received research and education support from Fujifilm, Aquilant Medical, Pentax, and Olympus. Dr. Murino has received research and education support from Fujifilm and Aquilant Medical. 
The authors

Alberto Murino, Nikolaos Koukias, Andrea Telese, Nikolaos Lazaridis, Edward J. Despott Royal Free Unit for Endoscopy, The Royal Free Hospital and University College London (UCL) Institute for Liver and Digestive Health,

Hampstead, London, United Kingdom

Corresponding author

Edward J. Despott, MD, FRCP, FASGE

The Royal Free Hospital and University College London (UCL) Institute for Liver and Digestive Health, Pond Street, Hampstead, London NW3 2QG, United Kingdom Fax: +44-20-74315261

edespott@doctors.org.uk

\section{References}

[1] Busuttil S], Goldstone J. Diagnosis and management of aortoenteric fistulas. Semin Vasc Surg 2001; 14: 1 - 7

[2] Bergqvist D, Björck M. Secondary arterioenteric fistulation - a systematic literature analysis. Eur J Vasc Endovasc Surg 2009; 37: $31-42$

[3] Despott E], Murino A, Butcher ] et al. First report of a secondary aortojejunal fistula visualized by small bowel capsule endoscopy. Dig Dis Sci 2012; 57: 256-257

\section{Bibliography}

DOI https://doi.org/10.1055/a-0665-4225

Published online: 11.1.2019

Endoscopy 2019; 51: E53-E54

(c) Georg Thieme Verlag KC

Stuttgart · New York

ISSN 0013-726X

\section{ENDOSCOPY E-VIDEOS}

https://eref.thieme.de/e-videos

回回 Endoscopy E-Videos is a free access online section, reporting 口if: on interesting cases and new techniques in gastroenterological endoscopy. All papers include a high quality video and all contributions are freely accessible online.

This section has its own submission website at

https://mc.manuscriptcentral.com/e-videos 